\title{
Bimbingan Teknis Tata Kelola Keuangan dan Anggaran Berbasis Kinerja Sekolah Tinggi Ilmu Kesehatan (STIKES) Muhammadiyah Palembang
}

\author{
Zulfikar $^{1}$, Rosida Nur Syamsiyati ${ }^{2}$, Ahmad Muttaqin ${ }^{3}$ \\ ${ }^{1}$ Universitas Muhammadiyah Surakarta, ${ }^{2}$ Institut Agama Islam Negeri Surakarta, \\ ${ }^{3}$ Universitas Islam Negeri Sunan Kalijaga Yogyakarta
}

\begin{abstract}
Article History ABSTRACT
Received 02.08.2019 Received in revised form 25.09.2019

Accepted 03.12.2019

Available online 16.12.2019

TECHNICAL ASSISTANCE FINANCIAL REPORTING AND BUDGETING BASED PERFORMANCE IN STIKES MUHAMMADIYAH PALEMBANG The purpose of this technical assistance activity were to provide knowledge and insights related to the financial management and performance based budgeting to the principal and budget user of STIKES Muhammadiyah Palembang and to help compile the work program. This activity was attended by 23 leaders from various levels.Materials that provided were, performance based budgeting, best practices, and financial reporting. The results of technical assistance for performance based budgeting indicate an increase in the ability of participants to develop budgets. Evaluation of the participants showed that they were very enthusiastic about following the activity from beginning to end.

KEYWORDS: Budgeting Based Performance, Financial Management, Technical Assistance.
\end{abstract} Attribution 4.0 International License, which permits unrestricted use, distribution, and reproduction in any medium, provided the original work is properly cited. (c) 2019 Zulfikar, Rosida Nur Syamsiyati, Ahmad Muttaqin.

\section{PENDAHULUAN}

Tahun 2019 Kementerian Riset Teknologi dan Perguruan Tinggi Republik Indonesia (Kemenristek Dikti) menerbitkan Surat Edaran No. 38/A.A3/SE/2019 tentang kewajiban pelaporan keuangan perguruan tinggi swasta (PTS) kepada Kementerian Riset Teknologi dan Perguruan Tinggi. Dalam Surat Edaran (SE) ditegaskan maksud dan tujuan pelaporan keuangan bagi PTS adalah dalam rangka pemeringkatan perguruan tinggi di Indonesia dan untuk mendorong akuntabilitas pengelolaan keuangan serta mengetahui kesehatan keuangan penyelenggaraan pendidikan tinggi. Ketentuan penyampaian laporan keuangan terbagi menjadi 3 kategori, yaitu: 1) laporan keuangan yang diaudit oleh akuntan publik bagi PTS yang memiliki lebih dari 3000 mahasiswa, 2) laporan keuangan

${ }^{1}$ Corresponding author: Program Studi Akuntansi Universitas Muhammadiyah Surakarta, Jl. A. Yani Pabelan Kartasura Surakarta. Email: zulfikar@ums.ac.id 
yang diverifikasi bagi PTS yang memiliki 1500 s.d 3000 mahasiswa, dan 3) laporan keuangan yang disetujui oleh yayasan/badan penyelenggara pendidikan tinggi terkait bagi PTS yang memiliki kurang dari 1500 (Kemenristekdikti, 2019).

Sekolah Tinggi Ilmu Kesehatan Muhammadiyah Palembang (Stikes MP) merupakan salah satu Perguruan Tinggi Muhammadiyah (PTM) yang sedang berbenah diri untuk merespon SE Kemenristek Dikti tersebut. Sebagai PTS yang berada dilingkungan Kemenristek Dikti dengan jumlah mahasiswa lebih dari 1500 orang, Stikes MP berkewajiban menyampaikan laporan keuangan yang diverifikasi oleh Akuntan Publik. Pimpinan Stikes MP berkomitmen untuk memenuhi tanggung jawab tersebut yang dibuktikan dengan partisipasinya dalam kegiatan Rapat Kordinasi Nasional (Rakornas) bidang Keuangan tanggal 18 Januari 2018 yang diselenggarakan di Lampung oleh Majelis Pendidikan Tinggi Penelitian dan Pengembangan Pimpinan Pusat Muhammadiyah (Diktilitbang PPM).

Jauh sebelum Kemenristek Dikti Menerbitkan SE tersebut, Majelis Diktilitbang PPM pada tahun 2017 telah menerbitkan buku Panduan Sistem Pengelolaan Keuangan PTM (Majelis Diktilitbang, 2017). Buku panduan tersebut mensyaratkan semua PTM mengelola keuangan yang mengacu pada anggaran berbasis kinerja pada saat menyusun rencana anggaran pendapatan dan belanja (RAPB). Anggaran berbasis kinerja merupakan sistem penganggaran yang mengukur luaran program kerja (Ninik \& Purwati, 2017). Luaran anggaran berbasis kinerja tidak hanya laporan realisasi anggaran melainkan laporan keuangan yang terdiri dari posisi keuangan, aktivitas dan arus kas (Oktavia, 2017). Dengan demikian pelaporam keuangan tersebut memenuhi syarat bagi PTM untuk diaudit oleh Akuntan Publik.

Berdasarkan hasil diskusi Lembaga Pembina dan Pengawas Keuangan PP Muhammadiyah (LPPK) dengan pimpinan, bagian keuangan serta para pengguna anggaran Stikes MP dihimpun informasi terkait pengelolaan keuangan yang belum efisien dan terstandarisasi, diantaranya sebagai berikut: (1) Para pengguna anggaran belum mengacu pada rencana strategis dalam proses penetapan program dan kegiatan. Dokumen perencanaan yang ada hanya formalitas untuk memenuhi akreditasi. (2) Belum terdapat instrumen yang baku dalam penyusunan anggaran pendapatan dan belanja. (3) Belum memiliki laporan keuangan yang menggunakan proses akuntansi yang berterima umum. Transaksi keuangan tercatat dalam buku kas masuk dan keluar tidak terdokumentasi kekayaan institusi. (4) Pengelola keuangan yang tidak berlatar belakang pendidikan akuntansi.

Uraian di atas menyimpulkan bahwa terdapat ketidakefisienan pengelolaan keuangan Stikes MP disebabkan para pemangku kepentingan belum memiliki kapasitas pengetahuan yang memadai dalam pengelolaan keuangan. Namun demikian para pimpinan, pengelola keuangan dan pengguna anggaran memiliki komitmen yang tinggi untuk memperbaiki tata kelola keuangan yang baik. Oleh karena itu semangat tersebut perlu mendapatkan apresiasi yang tinggi melalui kegiatan pendampingan teknis peningkatan kapasitas individu agar memiliki pengetahuan tentang pengelolaan keuangan yang baik dan terstandar. 


\section{METODE PELAKSANAAN}

Kegiatan pengabdian pada masyarakat ini dilakukan dengan pendekatan technical assistance. Pendekatan ini merupakan proses pengembangan kreatif bagi peserta agar memiliki karakter, yaitu: (1) menilai kesenjangan, kebutuhan, dan identifikasi respon potensial terhadap masalah yang dihadapi. (2) mengembangkan rencana strategis untuk perubahan jangka panjang. (3) menciptakan inovasi dalam menghadapi masalah baru (Soler, Cocozza, \& Henry, 2013). Materi yang diberikan pada kegiatan ini meliputi: performance based baudgeting, best practice dan praktik penyusunan instrumen anggaran.

Kegiatan ini diikuti oleh 23 orang peserta yang terdiri dari: 3 orang pimpinan perguruan tinggi (ketua, wakil ketua 1 dan 2), 16 orang pimpinan program studi (terdapat 8 program studi yang mesing-masing terdiri dari ketua dan Sekretaris program studi), 2 orang bagian keuangan dan 2 orang Badan Pengurus Harian (BPH) Perguruan tinggi. Peserta dikelompokkan menjadi dua kategori, sebagai berikut:

Tabel 1. Identifikasi Peserta Technical Assistance

\begin{tabular}{lll}
\hline Kelompok & Identifikasi Peserta & Jumlah \\
\hline Performance based Budgeting & Ketua, Wakil ketua & 3 \\
& Kaprodi dan Sekprodi & 16 \\
& Bagian Keuangan & 2 \\
& Pengurus Harian & 2 \\
\hline Jumlah & & 23 \\
\hline Akuntansi dan Laporan keuangan & Ketua, Wakil ketua & 3 \\
& Bagian Keuangan & 2 \\
& Pengurus Harian & 2 \\
\hline Jumlah & & 7 \\
\hline
\end{tabular}

Metode yang digunakan dalam pengabdian masyarakat ini terbagi dalam cara pelaksanaan dan evaluasi (Hidayat et al., 2019), sebagaimana ditunjukkan pada tabel berikut:

Tabel 2. Metode Kegiatan Pengabdian

\begin{tabular}{lll}
\hline Sesi & Metode & Instrumen Evaluasi \\
\hline Based Practice & Ceramah dan diskusi & Angket multiple choice \\
Pengenalan PBB & Ceramah dan diskusi & Angket multiple choice \\
TA PBB & Multi tasking & Isian formulir RAPB \\
TA Pelaporan Keuangan & Multi tasking & Isian formulir Akuntansi \\
\hline
\end{tabular}

PBB $=$ Performance based Budgeting

$\mathrm{TA}=$ Technical Assistance

\section{HASIL DAN PEMBAHASAN}

Kegiatan pengabdian ini dilakukan sesuai permintaan mitra (Stikes MP) berdasarkan hasil audit yang memberi rekomendasi untuk perbaikan proses pengelolaan keuangan. Selanjutnya mitra mengajukan usulan kepada Majelis Diktilitbang PPM untuk menyediakan tim konsultasi. Berdasarkan usulan tersebut, Majelis Diktilitbang PPM menyediakan tim untuk mendampingi mitra dalam kegiatan capacity building bagi para pengelola Stikes MP. Langkah berikutnya mitra membentuk kepanitiaan, menentukan tempat dan waktu kegiatan, serta menyusun round down acara. 
Rangkaian kegiatan pengabdian pada hari pertama (Selasa, 9 Juli 2019) diawali dengan pembukaan, sambutan-sambutan oleh Ketua Stikes MP dan Ketua Majelis Diktilitbang PPM. Setelah pembukaan acara dilanjutkan sesi-sesi materi, yang meliputi:

1) Kebijakan Majelis Diktilitbang PPM tentang tata kelola keuangan PTM.

2) Expose dan penjelasan hasil audit LPPK di Stikes MP

3) Analisis RAPB dan pemetaan rencana strategis Stikes MP

4) Pengenalan sistem penganggaran berbasis kinerja

Pada hari kedua (Rabu, 10 Juli 2019) kegiatan pengabdian dilanjutkan dengan pendekatan bimbingan teknis (technical assistance) yang terbagi menjadi beberapa sesi, yaitu:

1) Praktik anggaran berbasis kinerja

2) Praktik penatausahaan pelaksanaan anggaran

3) Praktik akuntansi dan penyusunan pelaporan keuangan

\section{Best Practice}

Pada sesi ini disampaikan kepada peserta terkait dengan pengalaman-pengalaman PTM lain dalam mensikapi kebijakan Majelis Diktilitbang. Tim Majelis Diktilitbang menyampaikan keberhasilan beberapa PTM yang telah mengaplikasikan sistem anggaran berbasis kinerja dan pelaporan keuangan. Pada sesi ini tim juga menyampaikan hasil audit LPPK dan menganalisis RAPB serta rencana strategis yang disusun oleh Stikes MP.

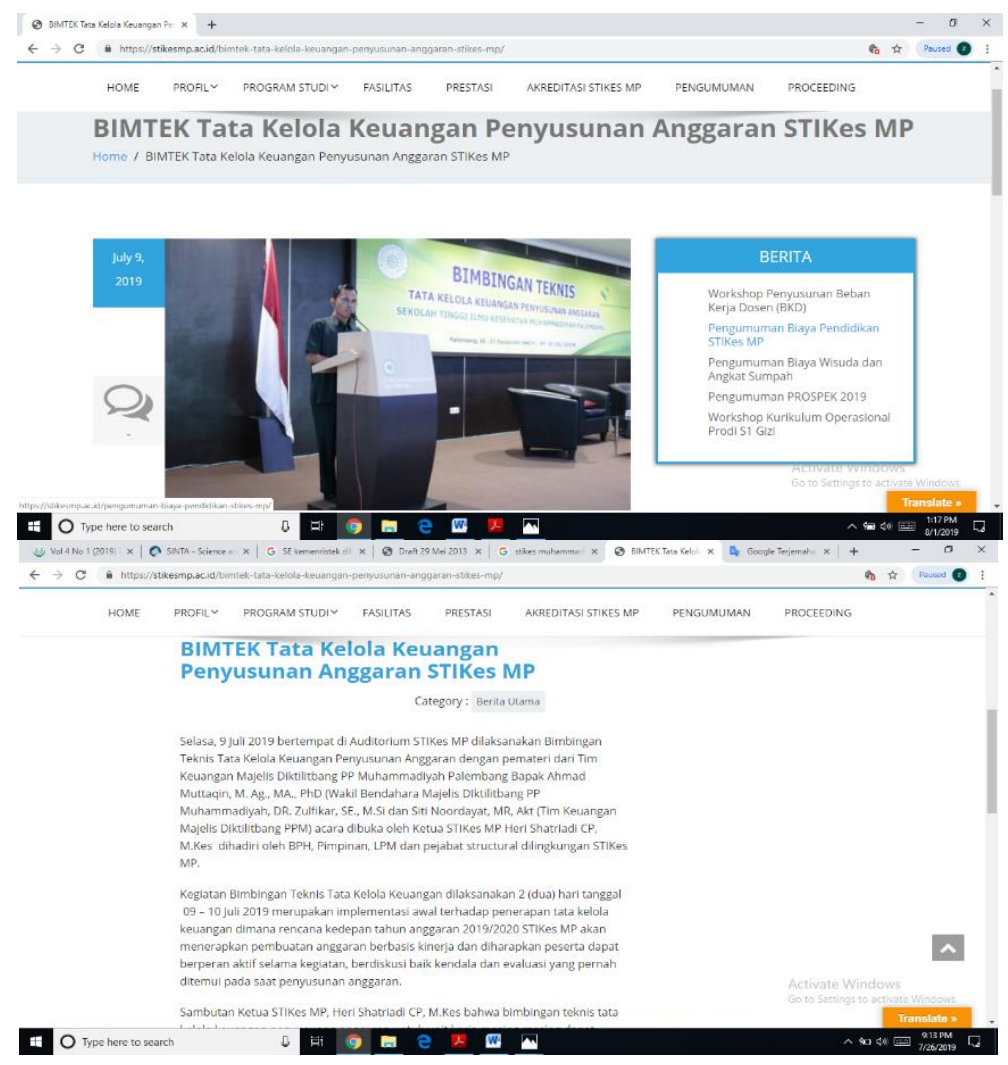

Gambar 1. Posting Kegiatan Pengabdian di laman https://stikesmp.ac.id 
Berdasarkan rangkuman diskusi pada sesi ini peserta mampu menilai kelebihan dan kekurangan institusi yang mereka kelola berdasarkan best practice. Hasil diskusi terhadap rekomendasi audit LPPK dan RAPB menunjuk-kan bahwa Stikes MP membutuhkan perbaikan tata kelola keuangan, yang meliputi perencanaan, penganggaran, pelaksanaan/penatausahaan, dan pelaporan keuangan (Octariani, Akram, \& Animah, 2017). Selanjutnya, pemateri melakukan pemetaan untuk menentukan perioritas kebijakan tata kelola keuangan yang akan diadopsi. Hal ini untuk tindak lanjut pada acara technical assistance.

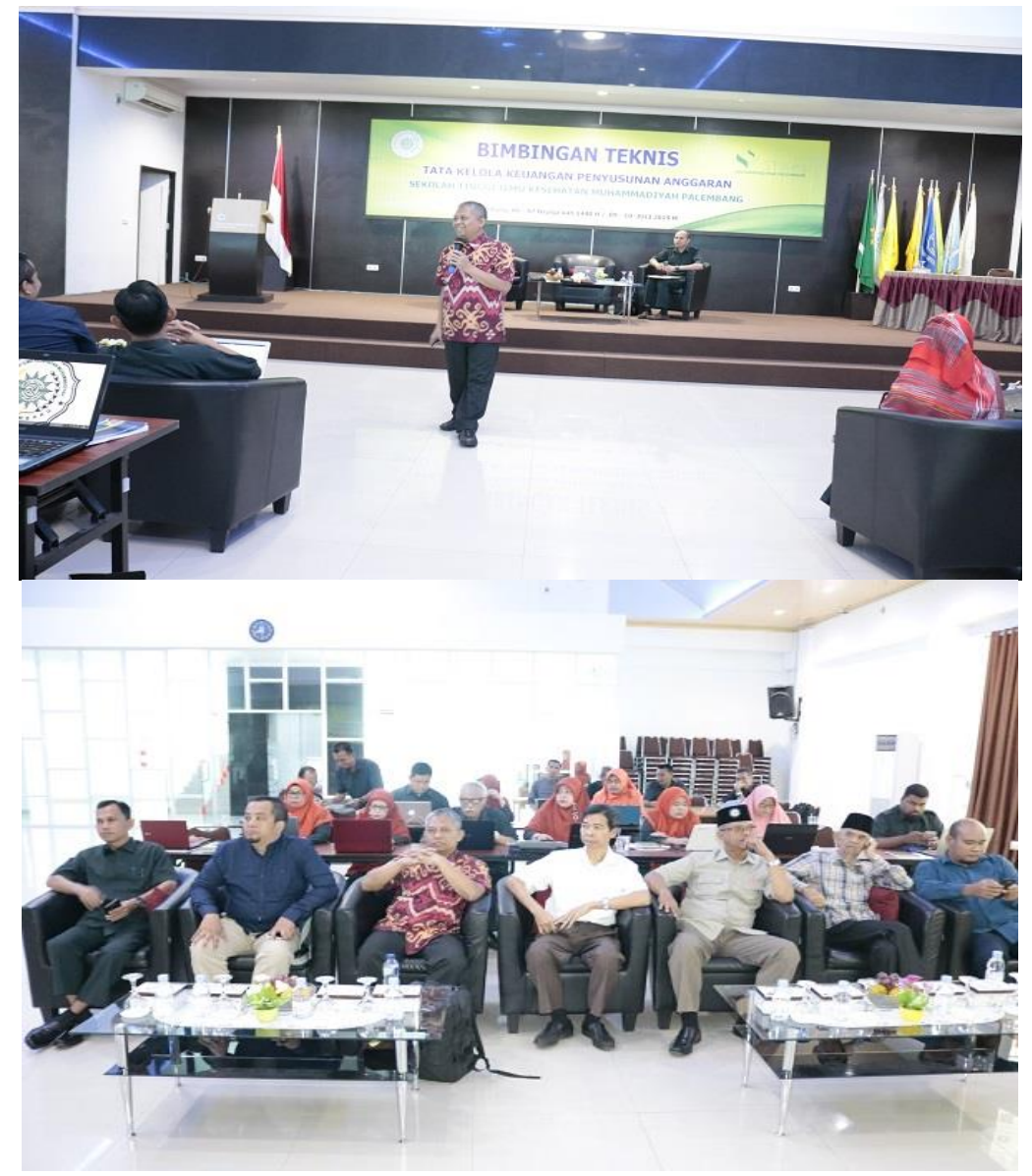

Gambar 2. Aktivitas Penyampaian Best Practice oleh Majelis Diktilitbang

\section{Pengenalan Anggaran Berbasis Kinerja (Performance Based Budgeting)}

Sebelum materi disampaikan, semua peserta dibagikan angket pengetahuan dalam bentuk perntaan multiple choice untuk mengetahui sejauh mana pemahaman mereka tentang anggaran berbasis kinerja (Ninik \& Purwati, 2017). Sesi ini bertujuan memperkenalkan kepada peserta panduan dalam menyusun anggaran berbasis kinerja (performance based budgeting). Pemateri menggunakan bahan bacaan yang diterbitkan oleh Majelis Diktilitbang yang sudah dibagikan kepada peserta.

Rangkuman hasil diskusi pada sesi ini menyebutkan bahwa penerapan anggaran berbasis kinerja memudahkan pengelola unit kerja dalam menetapkan time line, mengukur capaian, dan efektivitas kegiatan (Alain \& Melegy, 2017). Bagi unit kerja 
program studi implementasi sistem tersebut dapat disinkronkan dengan borang penilaian butir akreditasi Sembilan standar.

\section{Technical Assistance: Performance Based Budgeting}

Langkah-langkah sesi ini meliputi persiapan, pelaksanaan, dan persiapan. Ketiganya akan diuraikan sebagai berikut:

\section{Tahap Persiapan}

Pada tahap persiapan yang pertama dilakukan adalah memilih peserta yang akan dilibatkan dalam pendampingan. Peserta yang dipilih adalah pimpinan unit kerja (ketua, program studi, dan lembaga) masing-masing sebanyak 2 orang. Kedua, panitia menyiapkan instrument yang dibutuhkan. Ketiga, persiapan tempat kegiatan pendamping dan prasarana yang lain.

\section{Tahap Pelaksanaan}

Sebelum tahap ini dilakukan, panitia membagikan angket pengetahuan yang terkait dengan instrumen penyusunan RAPB. Kegiatan ini untuk tes awal bagi peserta agar diketahui peningkatan pengetahuan secara komprehensif.

Tahap pelaksanaan mencakup kegiatan peserta dalam menyusun RAPB unit kerja. Kegiatan tersebut mencakup, pertama mengevaluasi dokumen perencanaan unit kerja. Dokumen perencanaan merupakan hal penting dalam penyusunan RAPB. Peserta mereview dokumen rencana jangka panjang, jangka menengah, jangka pendek dan rencana operasional. Kedua, menentukan target capaian kinerja tahun sekarang berdasarkan dokumen renstra dan key performance index. Ketiga, menyusun evaluasi diri menggunakan analisis SWOT (kekuatan, kelemahan, peluang dan tantangan) (Suhalim, 2015).

Setelah dokumen perencanaan tersusun, setiap peserta yang mewakili unit kerja masing-masing diminta untuk mengisi formulir RAPB. Formulir pertama (Rencana Kerja 1) adalah isian rencana stratejik unit kerja, yang meliputi: visi, misi, tujuan dan strategi. Formulir kedua (Rencana kerja 2) adalah isian rencana kegiatan unit kerja, yaitu: peningkatan kualitas akademik, peningkatan kualitas kemahasiswaan, dan peningkatan kualitas administrasi umum dan keuangan. Formulir Ketiga (rencana kerja anggaran pendapatan/RKA Rinci 1) adalah isian perincian anggaran pendapatan. Formulir keempat (rencana kerja anggaran belanja/RKA rinci 2) adalah isian perincian anggaran belanja unit kerja.

\section{Tahap evaluasi}

Tahap evaluasi merupakan tahap terakhir pada kegiatan bimbingan teknis. Kegiatan ini mengevaluasi hasil kerja peserta pada saat pendampingan peserta menyelesaikan performance based budgeting. Hasil evaluasi seluruh peserta dilakukan dengan membandingkan tes awal dan hasil akhir pekerjaan selama tahap pelaksanaan. Perbandingan antara keduanya menunjukkan kenaikan kinerja peserta dalam mengikuti kegiatan technical assistance (Blase, 2009). 




Gambar 3. Aktivitas Technical Assistance Penyusunan Anggaran

\section{SIMPULAN}

Berdasarkan hasil pelaksanaan technical assistance secara umum disimpulkan bahwa performance based budgeting di Stikes MP sangat mendesak diberlakukan. Hasil pendampingan performance based budgeting menunjukkan kenaikan kemampuan peserta dalam menyusun anggaran. Evaluasi terhadap peserta menunjukkan bahwa mereka sangat antuasian mengikuti kegiatan dari awal hingga akhir.

\section{REFERENSI}

Alain, A. M. M., \& Melegy, M. M. A. H. (2017). Program and Performance Budgeting System in Public Sector Organizations: An Analytical Study in Saudi Arabian Context. International Business Research, 10(4), 157-166. https://doi.org/10.5539/ibr.v10n4p157

Blase, K. A. (2009). Technical assistance to promote service and system change. roadmap to effective intervention practices\# 4. Technical assistance center on social emotional intervention for young children. Tampa, Florida: University of South Florida. 
Hidayat, M. T., Faiziyah, N., Listiawati, V., Rini, I. F., \& Surahmat, S. (2019). Workshop Penyusunan Program Unggulan OSN di Madrasah Ibtidaiyah Muhammadiyah Tegalampel, Klaten. Jurnal Pengabdian Pada Masyarakat, 4(1), 1-10. https://doi.org/10.30653/002.201941.54

Kemenristekdikti. (2019). Surat Edaran Nomor 38/A.A3/SE/2019 Tentang Kewajiban Penyampaian Laporan Keuangan Perguruan Tinggi Swasta Kepada Kementerian Riset, Teknologi, dan Pendidikan Tinggi. Jakarta: Kemenristekdikti.

Majelis Diktilitbang. (2017). Panduan Sistem Pengelolaan Keuangan Perguruan Tinggi Muhammadiyah. Yogyakarta: PP. Muhamadiyah.

Ninik, \& Purwati, E. (2017). Analysis of Performance-Based Budgeting System Implementation in Improving Organizational Effectiveness, 19(6), 62-70. https://doi.org/10.9790/487X-1906026270

Octariani, D., Akram, A., \& Animah, A. (2017). Good governance, performance based budgeting and SKPD budget quality SKPD (The case of a structural model approach). JKAP (Jurnal Kebijakan dan Administrasi Publik), 21(2), 117-131.

Oktavia, R. (2017). The impact of an implementation performance based budgeting (PBB) on an efficiency of financial performance on local governance in Indonesia. International Journal of Scientific \& Technology Research, 6(8), 214-220.

Soler, M. A. R. K., Cocozza, J. J., \& Henry, A. L. A. N. (2013). Providing and receiving technical assistance: Lessons from Models for Change. Chicago: MacArthur Foundation.

Suhalim, S. (2015). Aplikasi metode analisis SWOT untuk merumuskan strategi bersaing pada PT Berkat Karya Lestari. Agora, 3(2), 392-399. 